\title{
Estudo da resposta tissular à endoprótese recoberta de jugular bovina em veia cava inferior de suínos
}

\author{
Bovine jugular covered stent-graft implanted in swine inferior vena cava - \\ a study of tissue response
}

\section{Cristina Ribeiro Riguetti Pinto ${ }^{1}$, Celso Luiz M uhlethaler Chouin'2, Gaudencio Espinosa Lopez ${ }^{3}$}

\section{Resumo}

O bjetivo: Avaliar a resposta tissular a uma endoprótese, com cobertura biológica heteróloga, implantada em veia cava inferior de suínos.

M étodo: D esenvolvemos uma endoprótese auto-expansível, revestida com um segmento de jugular bovina, conservada por processo $L$-hydro e suturada em um stent de aço inoxidável 316L. 0 dispositivo introdutor utilizado foi a bainha de liberação da endoprótese aórtica Taheri-Leonhardt (Flórida, EUA). Foram implantadas endopróteses em 10 suínos, todas na veia cava infra-renal. 0 s animais foram submetidos à flebografia peroperatória. À necropsia, após 2 meses, cada endoprótese foi retirada em bloco e analisada macroscopicamente, visando a avaliação da perviedade, aderência aos tecidos vizinhos e incorporação à parede venosa; e, histopatologicamente, visando a resposta histológica ao enxerto.

Resultados: $\mathrm{N}$ a análise macroscópica, todas as endopróteses en contravam-se pérvias e totalmente incorporadas à parede venosa, porém seis apresentavam trabeculações grosseiras no seu interior e quatro algum grau de fibrose perivascular. Três animais desenvolveram linfocele, uma retroperitoneal e as outras na parede abdominal. No estudo histopatológico, observamos reação inflamatória granulomatosa tipo corpo estranho em todos os casos, sendo predominante na camada média (80\%).

Conclusão: 0 modelo estudado apresentou baixa trombogenicidade, corroborando com a eficácia do meio de conservação e material escolhidos; porém, baixa biocompatibilidade, provavelmente pelo obstáculo imunológico dos xenoenxertos e resposta tissular exagerada do território venoso.

Palavras-chave: Endoprótese, bioprótese, veias jugulares, bovinos, veia cava inferior, histocompatibilidade.

1. Mestranda, Serviço de Cirurgia Vascular, Departamento de Cirurgia Geral, Faculdade de Medicina, Universidade Federal do Rio de Janeiro (UFRJ), RJ.

2. Doutorando, Serviço de Cirurgia Vascular, Departamento de Cirurgia Geral, Faculdade de Medicina, UFRJ, RJ.

3. Doutor, Professor Adjunto, Serviço de Cirurgia Vascular, Departamento de Cirurgia Geral, Faculdade de Medicina, UFRJ, RJ.

Artigo submetido em 18.04.06, aceito em 12.06.06.

J Vasc Bras 2006;5(2):81-8.

Copyright $\odot 2006$ by Sociedade Brasileira de Angiologia e de Cirurgia Vascular.

\begin{abstract}
O bjective: To evaluate tissue response to a bovine jugular vein covered stent when implanted in the swine inferior vena cava.

Method: We developed a self-expanding stent, using a segment of $L$-hydro conserved bovine jugular vein, which was trimmed and sutured to a 316L stainless steel stent. We used the Taheri-L eonhardt delivery system for aortic stent-graft deployment (Florida, USA). Ten handmadestent-grafts wereimplanted in 10 swine inferior venae cavae. All animals were submitted to perioperative venography. At necropsy, 2 months later, the stent-grafts were removed en bloc and histopathologic anal ysis was undertaken, in order to analyze its patency, adherenceto neighboring tissues and incorporation to the venous wall, as well as tissue response.
\end{abstract}

Results: All stent-grafts were patent and adherent to venous wall, but six presented with gross trabeculation and four had some degree of perivascular fibrosis at macroscopy. Three animals developed lymphocele, one in the retroperitoneal space and the others in the abdominal wall. At histopathology, we observed chronic inflammatory reaction with foreign body granulomatous response in all cases, with prevalence of the tunica media ( $80 \%)$.

Conclusion: The model presented low thrombogenicity, which corroborates the efficacy of the chosen means of preservation and material. H owever, there was low compatibility, probably due to the immunological obstacle of xenografts and exaggerated tissue response of the venous territory.

Key words: Stent-graft, bioprosthesis, jugular veins, cattle, inferior vena cava, histocompatibility.

0 tratamento de lesões traumáticas e processos estenóticos ou oclusivos venosos éum assunto de grande dificuldade e controvérsia terapêutical-4. Por se tratar de um território vascular cuja lesão apresenta menor impacto clínico eevolução mais lenta em rel ação à arterial, há uma carência de experiência e consenso na literatura. Com o advento da cirurgia endovascular, técnica minimamente invasiva, a indicação desse tipo 
de intervenção no território venoso é crescente $2-11$.

A angioplastiatransluminal venosa percutâneapode ser eficaz durante alguns meses, porém, em geral, as estenoses são muito resistentes, com alto índice de ineficácia primáriaereestenosea curto emédio prazo ${ }^{12}$. A utilização de stents representa um certo progresso, mas não definitivo. A maior parte dos pacientes, com exceção doscasos detratamento paliativo para estenoses neoplásicas, terá de submeter-se a várias intervenções endoluminais para manter a permeabilidade de seu sistema venoso epara prevenir uma eventual trombose, que, seaguda, podeter conseqüênciasdrásticas. Porém, os resultados, ainda queinferiores aos arteriais, competem com os obtidos com as cirurgias convencionais de grandes vasos dos sistemas das veias cava superior e inferior ${ }^{12,13}$.

A investigação de materiais biológicos para a confecção de endopróteses é recente ${ }^{14}$. A veia foi um dos primeiros enxertos utilizados, em sua forma autóloga ou heteróloga desnaturada ${ }^{15}$. Embora o en xerto venoso autólogo apresente 0 melhor resultado, necessita de procedimento cirúrgico para sua coleta e depende do patrimônio venoso do paciente ${ }^{16}$. Porém, as endopróteses biológicas oferecem algumas qualidades que os polímeros sintéticos não possuem, como a resistência à infecção, baixo perfil, maior complacência e maior biocompatibilidade ${ }^{16}$.

U ma série de processos celulares e moleculares complexos contribui para a cicatrização das en dopróteses. Esses processos cicatriciais refletem a resposta tissular ao implante de um corpo estranho no sistema vascular e resultam em quatro tipos de formações tissulares: trombo, neo-íntima, endotélio einfiltrado de células inflamatórias ${ }^{16,17}$. T anto a extensão quanto a localização de cada um dos quatro tipos tissulares são influenciadas por um número de fatores mecânicos relacionados ao implante da endoprótese, localização das hastes de metal do stent, tipo de polímero ou material biológico do enxerto emétodo de conservação utilizado ${ }^{16}$.

0 presente estudo foi elaborado para avaliar a respostatissular ao implante, nacava inferior desuínos, de uma endoprótese auto-expansível recoberta com segmento de veia heteróloga conservada em solução especial pelo processo L-hydro.

\section{M aterial e método}

Este estudo foi realizado no centro de pesquisa da Labcor Laboratórios, em Santa Luzia (M G ), e apro- vado pelo C omitê de Ética e Pesquisa em A nimais de Laboratório do D epartamento de C irurgia da UFRJ e pelo Comitê de Cuidados e U so de Animais do Centro de Pesquisa da L abcor Laboratórios, em Belo H orizonte (M G).

\section{Endopróteses}

A endoprótese foi estruturada por um stent constituído por três anéis de fio com secção redonda de 0,018", de aço inoxidável 316L, dobrados em ziguezague, tipo "alça de guardanapo", e conectados entre si longitudinalmente por um fio do mesmo material e perfil (barra conectora). Cada anel do stent media aproximadamente $12 \mathrm{~mm}$ de comprimento, com um total de 10 dobras eqüidistantes, totalizando cinco cristas e cinco vales. T odo o dispositivo apresentava em média 63 mm ( 47 mm-80 mm) deextensão por 15 mm (10 mm-22 mm) de diâmetro. 0 s diâmetros dos stents foram adequados aos segmentos de jugular bovina disponíveis. Já os diâmetros das endopróteses, escolhidas para cada animal, foram estipulados de acordo com o protocolo estabelecido por Gomez-Jorge et al. e confirmados empiricamente pela avaliação do diâmetro externo da cava sob visão direta ${ }^{18}$.

O ssegmentos dajugular de bovino foram extraídos de animais abatidos em idade adulta, no abatedouro municipal deSanta Luzia (M G ), aprovado pelo M inistério da Agricultura eV igilância Sanitária para essefim. A pósserem aparados, para eliminar o excesso detecido, e montados em suporte, receberam o tratamento de preservação pelo processo L-hydro.

0 processo L-hydro de conservação é dividido em três etapas distintas. A primeira combina a extração de antígenos, sob condições controladas, sem o uso de detergentes, surfactantes ou enzimas digestivas, com 0 mascaramento deantígenos remanescentespel o poliglicol, sob oxidação química controlada. Essa etapa é realizada em condiçõesfísicas específicas, queprotegem os componentes extracelulares, tais como o colágeno e a el astina. A segunda etapa consiste em um processo de incorporação ao tecido de um agente antiinflamatório não-esteróide (equival ente ao ácido acetilsalicílico) ede um agente antitrombótico (equival ente à heparina). A terceira e última etapa realiza a esterilização do tecido em fase aquosa de peróxido de hidrogênio $\left(\mathrm{H}_{2} \mathrm{O}_{2}\right)$.

Para o implante da endoprótese, foi utilizado o sistema liberador da endoprótese de aorta tipo T aheriLeonhardt (Flórida, EUA), composto por uma bainha 
coaxial, com um êmbolo propulsor (Figura 1). Os sistemas usados foram de calibres variados: 18-24F , sendo escolhidos conformea regra do " $n+4$ " desenvolvida in vitro por Gomez-J orge et al. ${ }^{18}$.

\section{Amostra}

Foram utilizados 10 suínos fêmeas de raça híbrida (cruzamento de Landracee LargeW hite), provenientes da Fazenda Córrego Fundo, Brumadinho (M G ). T odos os animais apresentavam-se saudáveis, com idade de 3 mesesepeso médio aproximado de $26 \mathrm{~kg}$, variando de 20 a $35 \mathrm{~kg}$. 0 sanimaisforam alimentados com ração de crescimento para suínos Socil G uyomarc'h, Cevadil $12,600 \mathrm{mg} /$ dia e água ad libitum.

\section{Procedimento cirúrgico}

Os animais foram submetidos a um jejum de 12 horas para al imentos sólidos e 6 horas para líquidos. $A$ viadeacesso venoso foi aveiamarginal daorelhadireita, eno ato anestésico foram utilizadas as seguintes drogas: sulfato de atropina na dose de $0,04 \mathrm{mg} / \mathrm{kg}$ intramuscular (IM) 20 minutos antes da indução; cloridrato de ketamina na dose de $7,8 \mathrm{mg} / \mathrm{kg}$ IM ; cloridrato de xilazina na dose de $2,2 \mathrm{mg} / \mathrm{kg} \mathrm{IM}$; tiopental sódico na dose de $8 \mathrm{mg} / \mathrm{kg}$ endovenoso e restante conforme necessidade; e succinilcolina na dose de 1 mg no início do procedimento.

A via de acesso foi a retroperitoneal, utilizando-se uma incisão abdominal oblíqua arqueada com concavidade medial em quadrante inferior direito. Após exposição, dissecção ereparo dasveiasilíacas externa, interna e comum, o animal foi anticoagulado com heparina sódica na dose de $350 \mathrm{UI} / \mathrm{kg}$. Foi puncionada a veia ilíaca comum direita e introduzida bainha curta $5 F$, pela técnica de Seldinger. Foi também realizada flebografia para delimitação do limite proximal (veia renal) e distal (bifurcação ilíaca) para o posicionamento da endoprótese. Após pinçamento distal dos vasos, foi introduzido sob fluoroscopia, por flebotomia longitudinal, o sistema de liberação apoiado sobre fio guia teflonado 0,035" x $145 \mathrm{~cm}$ com ponta em "J". Procedendo-seà liberação da en doprótese, foi realizadaflebografia de controle pelo próprio sistema liberador retraído distalmente e posterior fleborrafia com fio de polipropileno 7-0 (Figura 2). A anticoagulação foi revertida com cloridrato de protamina na dose de $1 \mathrm{ml}$ para cada 1.000 UI de heparina sódica administrados, e realizou-se síntese da parede abdominal por planos.

\section{Pós-operatório}

Após a cirurgia, os animais foram mantidos sob temperatura ambiente em compartimentosindividuais nos primeiros dias e em alojamento conjunto no período restante. Foram mantidos em regime de droga antiinflamatória por 3 dias consecutivos (flunixin meglumine $50 \mathrm{mg} /$ dia) eantibiótica por 7 dias (enrofloxacina), $5 \mathrm{mg} / \mathrm{kg} / \mathrm{dia}$.

\section{Sacrifício}

Após 2 meses do procedimento de implante da endoprótese, 0 animal foi anestesiado pela mesma técnica esacrificado com injeção endovenosa decloreto de

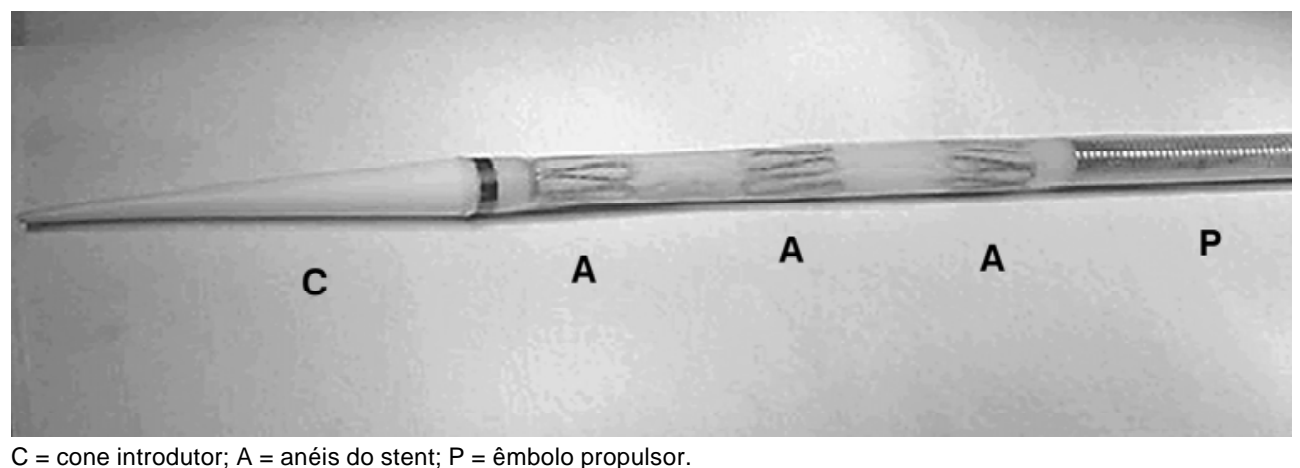

Figura 1 - Endoprótese montada no sistema liberador 


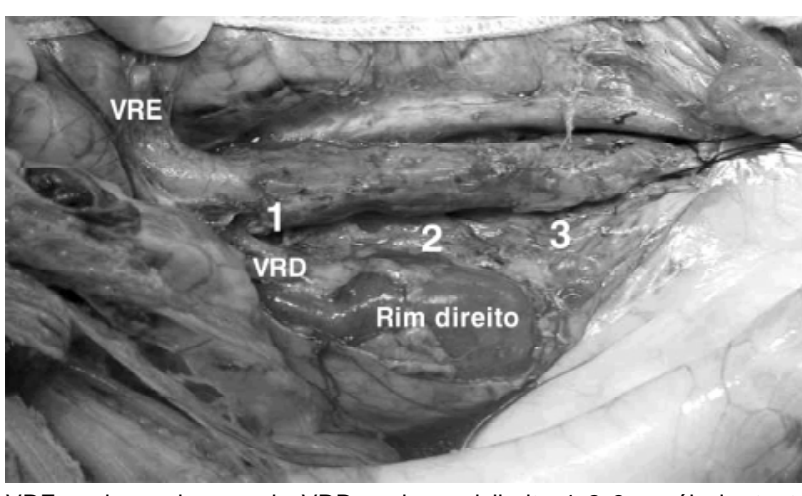

$\mathrm{VRE}=$ veia renal esquerda; $\mathrm{VRD}=$ veia renal direita; 1 , 2, 3 = anéis do stent

Figura 2 - Endoprótese implantada na veia cava infrarenal

potássio a $10 \%$ na dose de $20 \mathrm{ml}$ in bolus. 0 segmento de veia cava inferior foi retirado em bloco e fixado com solução de aldeído fórmico a 10\%.

\section{Análise macroscópica}

D eacordo com a avaliação das características internas e externas da peça, foi estabelecido um esquema de escore para comparação final dos resultados. A reação defibrosetissular com aderência a estruturasadjacentes foi pontuada com zero quando não ocorreu, 1 ponto quando foi moderada e 2 pontos quando intensa. A perviedade luminal foi pontuada com zero quando era total, 1 ponto quando houve trabeculações e 2 pontos quando da oclusão total do vaso. A incorporação da endoprótese recebeu zero quando totalmente incorporada ao vaso nativo, 1 ponto quando parcialmente incorporada (descolável ao manuseio) e2 pontosquando não incorporada (descolada).

\section{Análise microscópica}

Foram removidososstentscom técnica microcirúrgica e realizados cortes transversos nos segmentos em contato com o anel do stent (intersegmentos) efora dos anéis do stent (segmentos livres). O s segmentos foram incluídos em blocos de parafina e posteriormente submetidos a cortes histológicos medindo $4 \mu \mathrm{m}$ de espessura e corados com hematoxilina-eosina.

A avaliação microscópica quantificou a reação inflamatória nos intersegmentos e segmentos livres de anéis do stent, sendo leve quando $\leq 30 \%$, moderada quando $>30 \%$ e $\leq 70 \%$ e grave quando $\leq 70 \%$.

\section{Resultado}

\section{Evolução pós-operatória}

As 10 endopróteses foram liberadas com sucesso. 0 correu um posicionamento inadvertido, com 0 anel mais distal na veia ilíaca comum direita, porém sem repercussão clínica. Todos os animais permaneceram vivos atéo sacrifício. U m animal apresentou abcesso na parede abdominal, que regrediu com antibioticoterapia. T rês animais apresentaram linfocele, uma moderada com drenagem espontânea, uma gigante na parede abdominal e outra gigante na cavidade retroperitoneal; edoisanimaisapresentaram granuloma na parededistal e externa da peça, sendo que um destes desenvolveu linforréia perienxerto.

\section{Macroscopia}

À necropsia, não houve nenhum caso de oclusão vascular, sendo a maioria das peças (60\%) classificada com perviedade parcial (Figura 3), e o restante (40\%), como totalmente pérvias, conforme T abela 1. Encontramos um bom plano de dissecção em mais da metade (60\%) do grupo em estudo: em dois animais apresentando aderência leve, em ambos os casos próximo à bifurcação ilíaca, e outros dois animais apresentando aderência intensa, conformeT abela 1. Embora todas as endopróteses aparentassem total incorporação à parede venosa, duranteo manuseio do preparo histológico, três destas se mostraram descoláveis, ou seja, parcialmente aderidas, conforme $T$ abela 1.

Tabela 1 - Resultado da macroscopia

\begin{tabular}{cccc}
\hline $\begin{array}{c}\text { N úmero } \\
\text { do animal }\end{array}$ & Perviedade & Aderência & Incorporação \\
\hline 1 & 1 & 1 & 0 \\
2 & 1 & 0 & 0 \\
3 & 1 & 0 & 0 \\
4 & 0 & 0 & 0 \\
5 & 0 & 0 & 1 \\
6 & 1 & 2 & 0 \\
7 & 0 & 0 & 1 \\
8 & 1 & 2 & 0 \\
9 & 0 & 0 & 0 \\
10 & 1 & 1 & 1 \\
\hline
\end{tabular}

Perviedade: 0 = completa, 1 = parcial, 2 = oclusão; aderência à fibrose perivascular: 0 = nenhuma, 1 = leve, 2 = intensa; incorporação da endoprótese ao vaso: $0=$ total, $1=$ parcial, $2=$ nenhuma. 


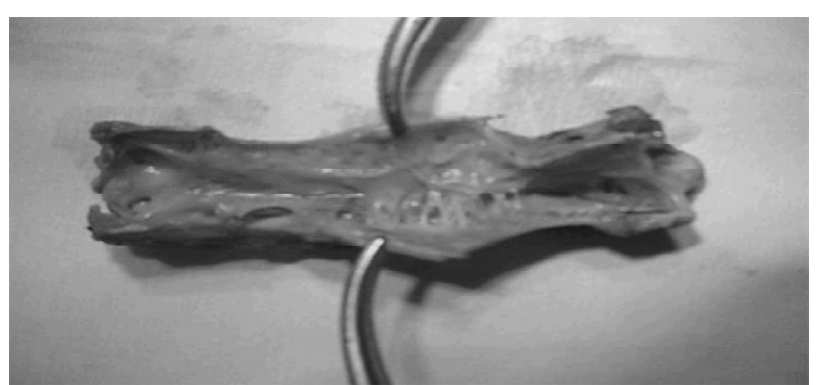

Figura 3 - M Macroscopia da peça (veia cava infra-renal) aberta longitudinalmente, evidenciando-se as trabeculações luminais, equival enteà perviedade parcial

\section{Microscopia}

Foi observada a presença de processo inflamatório crônico com reação granulomatosa tipo corpo estranho em todas as peças estudadas (Figura 4). A localização predominante da resposta inflamatória foi na camada média em $80 \%$ dos casos, e houve ausência da camada íntima nos quatro últimos, conforme Tabela 2. Os resultados de quantificação da resposta mostraram uma discreta diferença entre os cortes dos intersegmentos e dos segmentos livres de anéis do stent, sendo severa em $40 \%$ dos segmentos livres e em $50 \%$ dos intersegmentos; leve em $30 \%$ dos livres e $20 \%$ dosintersegmentos; e igualmente moderada em $30 \%$ de ambos, conforme T abela 2. Assim, a resposta severa predominou em um caso de corte nos intersegmentos, e a leve, em um caso de corte nos segmentos livres de anéis.

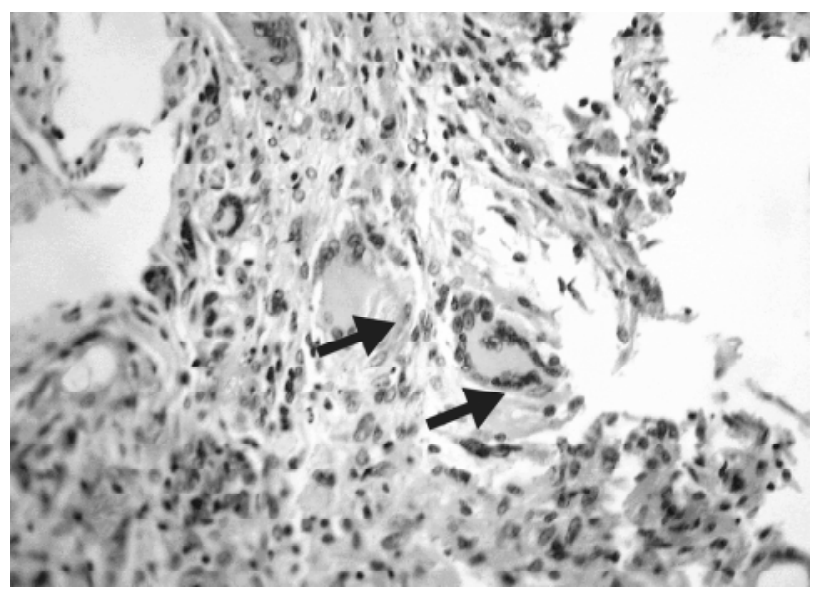

Figura 4 - M icroscopia com imagem de gigantócitos (setas)

\section{D iscussão}

D esde o início do século 20 que modelos animais têm sido utilizados para a pesquisa da doença vascular. $\mathrm{N}$ o entanto, um modelo ideal não existe, jáquenenhum reproduz perfeitamente a resposta humana à doença. $A$ histopatologia sugere que os vasos periféricos do porco doméstico e do coel ho são osquemais seassemelham ao modelo ideal, pois apresentam tamanho eacesso vascular semel hantes aos do homem, exibem quantidades substanciais de elastina e possuem íntima, média e adventícia comparáveis ${ }^{19}$. No entanto, as respostas cicatriciaissão menosintensasnaespéciehumanaquando comparadas às demais ${ }^{20}$. E os suínos têm uma tendência à hipercoagulabilidade e sistema fibrinolítico não tão ativo 21 .

N o nosso estudo, utilizamossuínos pela semel hança anatômica, morfológica e histológica do sistema vascular, além da facilidade de aquisição. N ão encontramos problema com o ganho ponderal, pois o prazo programado do experimento foi de 2 meses, não representando dificuldade no seu manejo. Embora os suínos apresentem tendência maior à hipercoagulabilidade e um sistema fibrinolítico menos ativo quando comparados aos humanos, não foi observado nenhum caso de trombose aguda do enxerto, estando, ao final do experimento, todas as endopróteses pérvias ou parcialmente pérvias. Em nossa opinião, esse fato demonstrou que a endoprótese biológica utilizada épouco trombogênica.

Fizemosumaabordagem qual itativa equantitativa, descrevendo a ocorrência, o tipo e a intensidade da resposta inflamatória, em se tratando da avaliação inicial de uma nova endoprótese e não de um dispositivo já em uso clínico. Assim, a escolha do tempo de 2 meses permitiu a análise da mortalidade precoce, complicações relacionadas ao procedimento ealterações macro e microscópicas da peça, como a perviedade e a resposta tissular.

$\mathrm{N}$ os estudos de viabilidade de stents farmacológicoscoronarianos, dispositivosjá em uso clínico regular, exige-se a avaliação do grau de inflamação, incluindose uma escala de lesão em cada local com metal, a descrição da inflamação (ausente ou tipo celular e localização) e uma escala de inflamação para todo 0 vaso, diferenciando-se cada camada e região ${ }^{19,21}$. Em nosso estudo de resposta tissular venosa, e não da viabilidade de um dispositivo já em uso clínico, observamoso grau deinflamação, aplican do-seuma escal a de reação inflamatória nos intersegmentos e segmentos livres de anéis. $\mathrm{N}$ os estudos de dispositivos coronaria- 
T abela 2 - Resultado da microscopia

\begin{tabular}{lcccc}
\hline $\mathbf{N}$ o do animal & $\begin{array}{c}\text { Segmentos } \\
\text { livres }\end{array}$ & Intersegmentos & $\begin{array}{c}\text { Local } \\
\text { predominante }\end{array}$ & $\begin{array}{c}\text { Presença } \\
\text { de íntima }\end{array}$ \\
\hline 1 & sev & sev & M -A & sim \\
2 & sev & mod & M & sim \\
3 & mod & sev & M & sim \\
4 & sev & sev & M - A & sim \\
5 & sev & sev & I & sim \\
6 & mod & mod & I & sim \\
7 & lev & mod & M & não \\
8 & lev & lev & M & não \\
9 & mod & sev & M & não \\
10 & lev & lev & M & não \\
\hline
\end{tabular}

Quantificação da reação inflamatória nos segmentos em contato com o anel do stent (intersegmentos) e sem contato (livres): resposta severa (sev), moderada (mod), leve (lev); local com maior predomínio da reação: íntima (I), média (M), adventícia (A); presença (sim) ou ausência (não) da camada íntima.

nos, a presença de inflamação ou depósito de fibrina deveseencontrar em níveisaceitáveis, ocorrendo em até $20 \%$ dos cortes e descrita como leve ou moderada, sem acelerar ou causar lesão vascular substancial ou esteno$\mathrm{se}^{19}$. Em nosso estudo, observamos reação inflamatória granulomatosa tipo corpo estranho em todos os casos, sendo severa em metadedosintersegmentoseem menos da metade (40\%) dos segmentos livres de anéis. Já as lesões vasculares, trabeculações grosseiras luminais, caracterizadas como endopróteses com perviedade parcial, foram encontradas em $60 \%$ das peças. Portanto, os níveis de reação inflamatória observados não foram de acordo com os aceitáveis na literatura para doença coronariana, macroscopicamente resultan do em lesões vasculares grosseiras em mais da metade dos casos.

Tentamos maximizar a perviedade do dispositivo, diminuindo o trauma mecânico com técnica microcirúrgica de preparo do enxerto, não realizando a pré dilatação eutilizando solução de baixa pressão on cótica associada à terapia antitrombótica através da técnica de preservação L-hydro. Porém, estudos parecem demonstrar que a hiperplasia neo-intimal ocorre com maior exuberância na presença de vel ocidade baixa de fluxo e em menor grau com a deformação circunferencial da paredevascular 22,23. A velocidade de fluxo estaria dire tamente relacionada à força de cisal hamento do sangue com a parede do vaso, um fator que determina a probabilidade e duração da aderência de elementos sangüíneosàíntima22. Em nosso estudo, o implante da endoprótese foi realizado no sistema venoso de suínos, com baixa força de cisal hamento emenor vel ocidadede fluxo, o que provavelmente propiciou a alta resposta proliferativa local.

0 tipo e a qualidade de enxertos vasculares biológicos disponíveis e em estudo são diversos, assim como também os métodos de preservação. São divididos basicamente em auto-enxertos, aloenxertos e xenoenxertos. O s auto-enxertos e aloenxertos, embora com melhor histocompatibilidade, apresentam menor disponibilidade, restringindo a sua utilização. M uita atenção tem sido dispensada, então, aos xenoenxertos e aos diferentes métodos de preservação. A distância filogenética e, portanto, o grau de discordância entre os antígenos dehistocompatibilidade maiores parecem ser determinantes na intensidade da reação de rejeição aos mesmos ${ }^{24}$. 0 sprimatasnão-humanosseriam, à primeira vista, os doadores mais certos; no entanto, o doador suíno pareceser o candidato maisadequado como fonte de xenoenxertos vasculares, por sua facilidade de procriação e manipulação genética, similaridade com 0 sistema cardiovascular humano e menor incidência de zoonoses transmissíveis ${ }^{24}$. 
A reestenose relativa ao implante de um stent no leito arterial parece ter uma forte correlação com a gravidade da lesão e o subseqüente espessamento neointimal e porcentagem estenótica ${ }^{25}$. Esta é uma lesão medial profunda, sendo predominantemente induzida no procedimento endovascular. O s eventos ocorridos minutos após esse procedimento são: adesão e agregação plaquetárias e trombose in situ ${ }^{26}$. A hipertrofia ea proliferação dascélulasmusculareslisas (CM L) mediais ocorre após 24-48 horas ${ }^{25,26}$. Embora o período seja espécie-dependente, aproximadamente 4-14 dias após a lesão, a migração dessas células para a camada íntima e a proliferação das mesmas ocorrem sob efeito de mitógenos da musculaturalisa ${ }^{26}$. A deposição dematriz extracelular eespessamento intimal caracteriza aúltima fase da patogênese, variando entre 14 dias e 3 me$\operatorname{ses}^{25,26}$.

O s fatores que causariam a reestenose parecem ser multifatoriais, incluindo-sea técnica de implante, fatores hemorreológicos, material e tamanho do stent, geometria das hastes do stent elocalização da doença no sistema vascular. U m dos fatores a que os stents podem estar relacionados é a lesão da parede venosa pelas suas hastes ${ }^{27}$. A proliferação deC M L éproporcional ao grau de lesão arterial causada pelo balão ou pelo stent ${ }^{27}$. Embora a associação entre a lesão da parede vascular e a proliferação de CM L seja bem conhecida, pouco se sabe sobre estratégias para a minimização do estresse sobre a túnica média ea lâmina elástica interna durante o procedimento endovascular.

Q uanto ao tipo de stent, os auto-expansíveis têm sido demonstrados como causadores de menor trauma intimal econseqüente hiperplasia neo-intimal, quando comparados aos balões expansíveis ${ }^{28}$. N este estudo, a força radial do stent auto-expansível foi intencionalmente utilizada para diminuir a estenose luminal produzida pela espessura da cobertura de enxerto venoso e ainda causar melhor adaptação ao ambiente venoso altamente complacente.

Comparando-se as coberturas da endoprótese com enxerto externo ou interno em relação ao stent, no estudo de T oyota et al., observou-se que a cobertura interna apresentou uma evolução pior, com oclusão ou estenose importante decorrente da hiperplasia intimal exuberante ${ }^{29}$. Essa hiperplasia intimal levou a uma reação inflamatória maior ea uma en dotelização atrasada eincompleta, quando comparadaà endoprótesecom enxerto externo. Em nosso estudo, optamos pela fixação interna do xenoenxerto venoso, o que talvez tenha sido responsável pela pobre endotelização da endoprótese, pel os três casos de adesão incompleta à parede da cava com descolamento ao manuseio e pela prevalência da perviedade parcial ou trabeculações grosseiras.

A cobertura interna, no entanto, preveniria o contato luminal com o metal, promovendo, assim, uma superfície interna lisa, com melhora dos resultados a longo prazo ${ }^{15,17}$. A principal limitação, no entanto, éa espessura do enxerto venoso, que causaria estenose do vaso. Em nosso estudo, a proteção ao contato do fluxo venoso com o stent foi provavel mentea explicação para a taxa nula de oclusão que obtivemos. Por outro lado, o contato do stent com a parede venosa resultou em maior reação tissular nesses locais. Encontramos também dificuldade para montagem da endoprótese no sistema de liberação, devido à espessura do enxerto venoso.

\section{C onclusão}

T entamos, neste estudo, associar um xenoenxerto a um stent para ampliar a eficácia no tratamento de patologias venosas, propiciando uma abordagem menos invasiva. Porém, deparamo-nos com o obstáculo imunológico ainda não transposto dos xenoenxertos e com o grande desafio do território venoso com respostas tissulares exageradas pelo fluxo lentificado e baixa força decisal hamento. 0 bservamos reação inflamatória granulomatosa tipo corpo estranho em todos os casos, sendo severa na maioria dos segmentos diretamenteem contato com o metal (intersegmentos). Além dessa reação tissular exagerada, macroscopicamente observamos trabeculações grosseiras em $60 \%$ dos casos, o que comprometeu a luz dos segmentos estudados, caracterizando perviedade parcial em sua maioria. A fixação interna do enxerto à endoprótese resultou em pobre endotelização, menor aderência à parede da veia cava e, provavelmente, contribuiu para o comprometimento da perviedade. Embora não tenha ocorrido nenhuma oclusão por tromboseou hiperplasianeo-intimal, o que corrobora com a eficácia do meio de conservação e material escolhidos, os resultados reservados apontam parauma baixa biocompatibilidade do dispositivo estudado.

\section{Referências}

1. Hurlbert SN, Rutherford RB. Subclavian-axillary vein thrombosis. In: Rutherford RB. Vascular surgery. $5^{\text {th }} \mathrm{ed}$. Philadelphia: W B Saunders; 2000. p. 1208-21. 
2. Raju S, O wen $\mathrm{S} J \mathrm{r}, \mathrm{N}$ eglen $\mathrm{P}$. The clinical impact of iliac venous stents in the management of chronic venous insufficiency. J Vasc Surg. 2002;35:8-15.

3. Yamakado K, N akatsuka A, T anaka N, et al. Portal venous stent placement in patients with pancreatic and biliary neoplasms invading portal veins and causing portal hypertension: clinical experience. Radiology. 2001;220:150-6.

4. YilmazS, Erdogan A, Luleci E. T ransvenousembolization and stent placement for an internal iliac arteriovenous fistula with central iliac vein occlusion. J Vasc Interv Radiol. 2004;15: 399-404.

5. Cronin P, M CPherson SJ, M eaney JF, M avor A. Venous covered stent: successful occlusion of a symptomatic internal iliac arteriovenous fistula. Cardiovasc Intervent Radiol. 2002;25:323-5.

6. D heer $S$, Joseph AE, D rooz A. Retroperitoneal hematoma caused by a ruptured pelvic varix in a patient with iliac vein compression syndrome. J V asc IntervR adiol. 2003;14:387-90.

7. KaneokaY, Yamaguchi A, I sogai M , H ori A. Intraportal stent placement combined with portal vein embolization against advanced gallbladder carcinoma. Surg T oday. 1998;28:862-5.

8. K reienberg PB, C hang, BB, D arling RC 3rd, et al. Long-term results in patients treated with thrombolysis, thoracic inlet decompression, and subclavian vein stenting for PagetSchroetter Syndrome. J V asc Surg. 2001;33:S100-5.

9. Savader SJ. Inferior vena cava filters. In: Trerotola SO, Savader S] , D urham J. V enous I nterventions. Fairfax: SC VIR Syllabus; 1995. p. 276-92.

10. Sharafuddin M J, Sun S, H oballah JJ, Youness FM , Sharp WJ, Roh BS. Endovascular management of venous thrombotic and occlusive diseases of the lower extremities. J Vasc Interv Radiol. 2003;14:405-23.

11. Yamakado K, N akatsuka A, T anaka N, Fujii A, Terada N, Takeda $\mathrm{K}$. M alignant portal venous obstructions treated by stent placement: significant factors affecting patency. J V asc Interv Radiol. 2001;12:1407-15.

12. Picard JD, Barrelier M T, J offreF. Veia normal. In: Picard JD, Barrelier M T, J offre F. A veia - sua imagenologia. São Paulo: Lemos; 2003. p. 14-40.

13. Stock KW, Jacob AL, Proske M, Bolliger CT, Rochlitz C, Steinbrich $W$. Treatment of malignant obstruction of the superior vena cava with the self-expanding wallstent. Thorax. 1995;50:1151-6.

14. Schachner T, Z ou Y, O berhuber A, et al. Local application of rapamycin inhibits neointimal hyperplasia in experimental vein grafts. Ann Thorac Surg. 2004;77:1580-5.

15. Schellhammer $F, H$ aberstroh J W akhloo AK, G ottschalk $E$, Schumacher $M$. Vein graft coated vascular stents: a feasibility study in a canine model. Cardiovasc Intervent Radiol. 1998;21:158-64.

16. Dolmatch $B L$. H ealing response to vascular stent-grafts. J V asc Surg. 2000;31:1285-9.

17. Schellhammer $F, W$ ahkloo AK, N agursky H, Schumacher $M$. $V$ ein graft-coated stents for endovascular occlusion of canine experimental arteriovenous fistulae. Invest Radiol. 1999;34: 22-7.
18. Gomez-J orge J, Venbrux AC, M agee C. Percutaneous $D$ eployment of a valved bovine jugular vein in the swine venous system: a potential treatment for venousinsufficiency. J Vasc Interv Radiol. 2000;11:931-6.

19. Schwartz RS, Edelman ER, Carter A, et al. Preclinical evaluation of drug-eluting stents for peripheral applications: recommendationsfrom an expert consensusgroup. Circulation. 2004;110:2498-505.

20. M ason RG, Read M S. Somespecies differences in fibrinolysis and blood coagulation. J Biomed M ater Res. 1971;5:121-8.

21. N arayanaswamy $M, W$ right $K C, K$ andarpa K. Animal models for atherosclerosis, restenosis, and endovascular graft research. J Vasc Interv Radiol. 2000;11:5-17.

22. Dobrin PB, Littooy FN, Endean ED. M echanical factors predisposing to intimal hyperplasia and medial thickening in autogenous vein grafts. Surgery. 1989;105:393-400.

23. M orinaga K, Eguchi H, M iyazaki T, O kadomeK, Sugimachi $K$. Development and regression of intimal thickening of arterially transplanted autologous vein grafts in dogs. J V asc Surg. 1987;5:719-30.

24. M iller VM, Reigel MM, Hollier LH, Vanhoutte PM. Endothelium-dependent responses in autogenous femoral veins grafted into the arterial circulation of the dog. J Clin Invest. 1987;80:1350-7.

25. I $\mathrm{JH}$, Fuster V, Badimon L, Badimon J, T aubman M B, Chesebro JH. Syndromes of accelerated atherosclerosis: role of vascular injury and smooth muscle cell proliferation. J Am Coll Cardiol. 1990;15:1667-87.

26. Phillips-H ughes J, Kandarpa K. R estenosis: pathophysiology and preventivestrategies. J V asc Interv Radiol. 1996;7:321-33.

27. Rogers C, Edelman ER. Endovascular stent design dictates experimental restenosis and thrombosis. Circulation. 1995; 91:2995-3001.

28. W akhaloo AK, Schellhammer F, de V ries J, H aberstroh J, Schumacher M . Self-expanding and balloon-expandablestents in the treatment of carotid aneurysms: an experimental study in acaninemodel. AJ N R AmJ N euroradiol. 1994;15:493-502.

29. Toyota N, Pavcnik D, VanAlstine W, et al. Comparison of small intestinal submucosa-covered and noncovered nitinol stentsin sheep iliac arteries: a pilot study. J V asc Interv Radiol. 2002;13:489-98.
Correspondência:
Cristina Ribeiro Riguetti Pinto
Rua Raul Pompéia, 144/704 - Copacabana
CEP 22080-000 - Rio de Janeiro, RJ
Tel: (21) 9873.3328
Fax: (21) 2249.2346
E-mail: crisriguetti@uol.com.br 